Espacio, Tiempo y Forma, Serie IV, Historia Moderna, t. 17, 2004, págs. 163-185

\title{
Orígenes familiares y carrera profesional de Julián de Arriaga, Secretario de Estado de Marina e Indias (1700-1776)
}

\author{
María Baudot MonRoY \\ UNED. Madrid
}

\section{RESUMEN}

La Secretaria de Marina surgida de las reformas administrativas de Felipe $V$ con la finalidad de ocuparse especificamente de los asuntos de la Marina, fue dirigida durante el siglo XVIII por diez y seis secretarios de Estado de Marina. Actualmente sólo contamos con estudios solventes sobre aquellos cuya gestión reformadora de la Marina destacó sobre la de los demás. Julián de Arriaga fue uno de los secretarios de Marina de los que apenas conocíamos unos rasgos. Este trabajo nos acerca al hombre que fue y a su familia, y da a conocer su carrera como marino de guerra, desarrollada durante la primera mitad del siglo, antes de acceder a la cartera de Marina.

\author{
ABSTRACT \\ One of the reforms that king Philip $V$ did to \\ modernice the Spanish administration was \\ to create a ministry for the Navy. During \\ the 18th. century this ministry had sixteen \\ different ministers. For the moment we \\ know only the biography of the most \\ outstanding ministers, those who did \\ fundamental reforms for the Spanish \\ Navy. Julian de Arriaga is one of the \\ ministers of the Navy of whom we know \\ only some few characteristics. This article \\ deals with his family and his career as a \\ naval oficer before his promotion to the \\ ministry in 1754.
}

"Nuestro conocimiento sobre la biografía de los españoles, incluso la de aquiellos de gran importancia histórica, es terriblemente limitado. Peor es aún el desconocimiento casi absoluto en que hay que moverse con personajes de segunda fila, pero de gran importancia en la vida del país y en el desarrolio del Estado. Resulta asombroso lo poco que sabemos de las personas que deciden, preparan, aconsejan y ejecutan acciones políticas".

John Elliott

La Secretaría de Estado de Marina e Indias fue creada por Felipe $V$ mediante un decreto promulgado el 30 de noviembre de 1714, cuando, recién acabada la Guerra de Sucesión, decidió reformar el esquema de gobierno existente. La anti- 
gua Secretaría del Despacho Universal fue sustituida por cuatro nuevas secretarías independientes: Estado, Justicia, Guerra y Marina e Indias. La reforma supuso que por primera vez los asuntos de la Marina contaran con un departamento propio.

De los diez y seis secretarios de Marina nombrados por los distintos monarcas durante el siglo XVIII sólo la labor de unos pocos ha conseguido posterior reconocimiento. Numerosos trabajos sobre el siglo XVIII han destacado que la Marina debe su segunda Edad de Oro a José Patiño, José del Campillo y Zenón de SomodeviIla, marqués de la Ensenada. Ahora bien, también estos personajes y sus respectivas obras de gobierno contaban con varios estudios solventes, precisamente porque la historiografía los había consagrado como los actores principales del proceso de reformas que propiciaron la consolidación de la Real Armada de la llustración como una gran fuerza naval.

Estos trabajos, simultáneamente, desplazaron como actores secundarios a los otros trece ministros restantes, hasta el punto de que sus nombres con el tiempo han ido cayendo en el olvido, y sus respectivas gestiones de gobierno al carecer de estudios solventes han quedado ensombrecidas, algunas incluso ignoradas, por la brillantez de las de Patiño, Campillo y Ensenada.

Parafraseando a John Elliott en este caso concreto, es asombroso lo poco que sabemos sobre estos ministros considerados como actores de segunda fila por la historiografía, pero que sin embargo decidieron, prepararon, aconsejaron y ejecutaron acciones políticas.

Uno de estos personajes olvidados por la historiografía es Julián de Arriaga y Ribera, secretario de Marina e Indias desde el 22 de julio de 1754 hasta su fallecimiento el 28 de enero de 1776, a pesar de que, en primer lugar, hay una serie de peculiaridades en el personaje que deberían haber reclamado la atención de los estudiosos de la Marina del siglo XVIII, como el que fuera el primer marino de guerra de la Real Armada que llegó a ser ministro de Marina, o el que entre los diez y seis secretarios de Marina del siglo XVIII f́uera el que más tiempo estuvo en el cargo, o el que sirviera a dos monarcas: Fernando VI y Carlos III que como es sabido propiciaron políticas muy distintas.

Sin olvidar en segundo lugar, que durante su ministerio la Marina fue protagonista e instrumento de relevantes hechos políticos, consecuencia, tanto dei cambio de mentores que, para la política de neutralidad de Fernando VI, supuso el nombramiento como secretario de Estado de Ricardo Wall; como del cambio de rumbo político que significó la enérgica decisión de Carlos III, tras acceder al trono español en 1759, de defender la integridad de su imperio. El desarrollo de la Marina no cejó en ninguna de las etapas del largo ministerio de Arriaga, si bien las decisiones políticas supusieron ritmos y lenguajes distintos que, no obstante, propiciaron que la Marina llegara a convertirse en una fuerza naval capaz de defender el imperio ultramarino agredido seriamente por una Inglaterra en plena expansión mercantil. 
Los hechos acontecidos durante el ministerio de Arriaga, aunque son conocidos, reclaman una revisión a partir de una investigación más profunda de quien tomó las decisiones y ejecutó las acciones políticas.

Nuestro objetivo en este trabajo es acercarnos al hombre y al marino que, tras una larga carrera en la Real Armada, se convirtió en un poderoso ministro de Marina e Indias. Para ello a través de documentación archivística hemos reconstruido sus orígenes familiares y su biografía profesional como marino de guerra de la Armada hasta el momento en que deja de navegar para convertirse en un miembro de la élite administrativa de la España del siglo xVIII, paso decisivo para acceder a la cartera de Marina e Indias.

\section{LA FAMILIA ARRIAGA}

El 19 de diciembre de 1700, estando sus padres de paso en Segovia', donde su abuelo paterno, Julián Manuel de Arriaga y San Vítores, caballero de la Orden de Alcántara ${ }^{2}$, era Corregidor, nació Julián Manuel de Arriaga y Rivera, convirtiéndose en el cuarto hijo del matrimonio formado por Diego Luis de Arriaga y San Martín y María Rivera y Duque de Estrada3. Diego de Arriaga había nacido en Burgos siendo bautizado a los pocos dias, según la costumbre, concretamente el 14 de noviembre de 1671 en la parroquia de San Esteban, de la que habian sido feligreses varias generaciones de la familia, celebrándose en ella muchos bautizos y matrimonios familiares ${ }^{4}$. María, por su parte, habia nacido en Simancas, recibiendo las aguas bautismales el 31 de julio de $1679^{5}$, y tanto su familia paterna, los Rivera, como la materna, los Duque de Estrada, eran naturales de Valladolid, ciudad que junto con la de Burgos serán los escenarios en los que se va a desarrollar la vida de la mayoría de los miembros de la familia Arriaga y Rivera.

1 El marqués de Lozoya, regidor perpetuo de la cilidad, y el marqués de Bracamonte, entre otros testigos naturales de Segovia consultados, que conocian personaimente tanto a Julián de Arriaga como a sus padres y abuelos, asi lo declararon en 1717 a los comisionados que realizaron las pruebas de limpieza de sangre y probanza de nobleza, previas al ingreso de Arriaga en la Orden de San Juan de Jerusalén. Archivo Histórico Nacional (en adelante A.H.N.) Sección Ordenes Militares - San Juan de Jerusalén (en adelante OO.MM.), exp. 23.326.

2 A.H.N., OO.MM. Exp. 123.

3 Habian contraido matrimonio en la parroquia de San Salvador de Valladolid el 20 de Julio de 1695 , según consta en el libro parroquial de casamientos, años 1685-1771, fol. 81. A.H.N., OO.MM. Exp. 664 y 23.326 .

4 Sirvannos como ejemplo cercano a nuestro personaje el matrimonio de los abuelos paternos, Julián Manuel y Casilda Teresa de San Martín, celebrado el 17 de diciembre de 1668, según consta en el libro de casamientos de dicha parroquia para los años 1601-1672, folio 145, A.H.N., OO.MM. Exp. 664; o el bautizo de su padre, Diego l.uis de Arriaga, libro de bautismos, años 1601-1703, folio 8, A.H.N., OO.MM. Exp. 23.326; o los bautizos de sus hermanas: Ana Maria, celebrado el 20.11.1702, libro parroquial de bautizos, años 1671-1703, folio 459, A.H.N., OO.MM. Exp. 52; Joaquina, celebrado el 17.3.1706, libro parroquial de bautismos que empieza en 1703, fol. 98, A.H.N., OO.MM. Exp. 53; y Manuela, celebrado el 5.1.1704, libro parroquial de bautismos año 1703, fol. 11, A.H.N., OO.MM. Exp. 54.

${ }_{5}$ Parroquia del Salvador de Simancas, libro parroquial de bautizos, años 1649-1669, fol. 85, A.H.N., OO.MM. Exp. 23.326. 
El niño Julián fue bautizado en la iglesia parroquial de San Sebastián de Segovia el día 29 de diciembre ${ }^{6}$, siendo su padrino de bautismo su tío paterno Juan Pablo, capitán del ejército y caballero de la Orden de San Juan ${ }^{7}$. En años posteriores nacieron hasta seis hermanas más de Julián, y teniendo en cuenta lo mucho que se preocupó del bienestar económico de varias de ellas durante su vida, como veremos más adelante, debieron de constituir una familia unida y bien avenida. El abuelo paterno, Julián Manuel, siguiendo la tradición de su padre y abuelo, habia sido regidor y corregidor en varias ciudades castellanas, como Ávila, Segovia o Burgos, tierra de sus antepasados y la suya propia, siendo estas ciudades lugar de nacimiento no sólo de sus hijos, sino también de algunos de los nietos, bien por encontrarse los padres viviendo con los abuelos circunstancialmente, como ocurrió con Julián, o bien por los cargos de regidor y corregidor que, en Ávila, Carmona, Guadalajara o el mismo Burgos, también ejerció Diego de Arriaga llevando consigo a su numerosa prole. Tanto Julián Manuel, abuelo, como su primogénito, Diego, como el hijo mayor de éste, Cayetano, hermano mayor de nuestro personaje, figuraron en los sucesivos padrones y libros de fianzas de la villa de Huermeces (Burgos) como "exentos de pagar la moneda forera» ${ }^{8}$, es decir, gozaron de la condición de nobles no residentes.

Poco sabemos de la infancia de los hermanos Arriaga: sólo que muchos de ellos abandonaron muy pronto el hogar familiar. Tres de las hermanas de Julián, Ana María, Manuela y Joaquiria, profesaron como religiosas Comendadoras de la Orden de Santiago, ingresando en el convento de Santa Cruz de Valladolid en 1711 , con nueve, siete y cinco años de edad respectivamente ${ }^{9}$, lo que significa que abandonaron definitivamente el hogar familiar siendo unas niñas. Su hermano Miguel ${ }^{10}$ también salió muy joven de la casa paterna para iniciar como cadete su carrera militar, según lo que declararon en 1778 bajo juramento los testigos que lo conocieron, al ser interrogados por los comisionados de realizar el expediente de limpieza de sangre y probanza de nobleza para ingresar en la orden de Santiago de su hijo Miguel Arriaga Parisani ${ }^{11}$.

La hermana mayor de Julián, Maria Teresa, había nacido en 1696 en Ávila ${ }^{12}$, "de paso", como se hace constar en la partida de bautismo, al estar sus padres vi-

${ }^{6}$ Libro parroquial de bautizos que empieza el 3.1.1655, folio 23, primera plana, primera partida, A.H.N., OO.MM. Exp. 23.326.

7 Habia nacido en Burgos en 1684, entrando en la orden de San Juan como paje a los doce años, según consta en su expediente de ingreso en la orden. A.H.N., OO.MM, exp. 23.325.

a Copias notariales de los goces de nobleza de la Baronía de Huermeces en A.H.N., OO.MM. Exps. 644 y 3926.

9 A.H.N., OO.MM, exps. 52,53,54 respectivamente. Para su manutención se hizo un depósito de 100 ducados de plata. A.H.N., OO.MM. Expedientillo 6651. Además, su madre, María Rivera, las excluyó junto a otras hermanas religiosas de su testamento por haberlas dotado a todas ellas convenientemente para ingresar como religiosas. A.H.N., OO.MM. Exp. 644.

${ }^{10}$ Había nacido el 17 de noviembre de 1699. Parroquia de San Juan Bautista de Ávila, libro parroquial de bautismos, años 1630-1703, fol. 508-509, A.H.N., OO.MM. Exp. 664.

11 A.H.N., OO.MM, exp. 664.

12 Partida de bautismo en la parroquia de San Juan Bautista, libro parroquial de bautismos, años 1629-1703, fol. 4 ?2. 
viendo en casa del abuelo paterno, por ser Diego en ese momento corregidor de la ciudad, como también lo era el abuelo Julián Manuel. Maria Teresa contrajo matrimonio en 1719, en Guadalajara ${ }^{13}$, con José del Hierro, vizconde de Palazuelos.

Otras dos hermanas, Josefa y Micaela, profesaron como religiosas de Santo Domingo en el convento de Portaceli de Valladolid, en el que también era religiosa su tía paterna, Juliana Teresa, quien había sido madrina de bautismo de todas sus sobrinas. La menor de todos los hermanos, Casilda, permanecía soltera y residía en Burgos en casa de su abuela paterna cuando en Valladolid en 1730 murió su madre, María de Rivera, quien la encomendó de manera especial en su testamento:

«[...] y le pido y encargo que con especialidad cuide de la Señora Doña Casilda su hija de la otorgante que aún está por tomar estado..." ${ }^{14}$

Como hijo segundón de la nobleza provincial no titulada y sin suficientes rentas, el destino de Julián se encontraba, en las filas de la milicia, en las del clero o en las de la reformada administración estatal borbónica, donde tanto su padre, Regidor y Alcalde Mayor perpetuo de Burgos ${ }^{15}$, como su abuelo Julián y demás antepasados directos, habían hecho carrera.

Precisamente éste será el destino de su hermano mayor, Cayetano ${ }^{16}$, quien llegará a ser Intendente de Palencia y Regidor de Burgos, siguiendo la tradición familiar de los primogénitos. En cambio, tanto el segundo varón de la familia, Miguel, como Julián se decantarán por la vida militar, aunque dentro del marco religioso de la Orden de San Juan de Jerusalén en la que ambos ingresarán ${ }^{17}$. Julián, en 1717, a los diez y siete años, convirtiéndose en Caballero de Justicia de la misma, lo que explica su posterior fama de "santurrón sincero" ${ }^{18}$ y el que permaneciera célibe, puesto que el profesar implicaba hacer vida de religioso a efectos del derecho canónico, practicando los votos de obediencia, pobreza y castidad.

En el siglo XVIII la pertenencia a la Religión de San Juan implicaba a sus caballeros, profesos o no, además de tener que acudir a la liamada que los superiores de la Orden hacían en situaciones críticas a sus miembros, dedicar unos años

13 Partida de matrimonio en la parroquia de Santo Tomé de Guadalajara, libro parroquial de casamientos, años 1616-1736, fol. 111. En realidad, María Teresa y José habian contraido matrimonio en julio de 1718 en la parroquia de Santiago, pero éste se inscribió el 12.1.1719 en la parroquia de la que eran feligreses. A.H.N., OO.MM., exp. 3926 664.

${ }^{14}$ Copia del testamento de Maria de Rivera autentificada notarialmente, en A.H.N., OO.MM. Exp.

15 F. ABBad y D. Ozanam: Les intendants espagnols du XVIlle siècle. Madrid, 1992. pp. 55-56.

16 F. AbBad y D. Ozanam: Les intendants.... pp. 55-56.

17 Aurique no hemos podido encontrar ei expediente de ingreso en la Orden de San Juan de Miguel, en el de su hijo Migue! Arriaga y Parisani, que fue caballero de Santiago, A.H.N., OO.MM, exp. 664, hay una copia autentificada notarialmente de una dispensa concedida por Benedicto XIV para que siguiese recibiendo una renta del obispado de Palencia una vez casado, y en ella consta que fue caballero sanjuanista no profeso.

18 A. FERrER Del Rio: Historia del reinado de Carlos III en España, edición facsimil, Madrid, 1986, vol 1, pp. 249-250. Primera edición, Madrid, 1898. 
al senvicio de la misma, atendiendo personalmente a los enfermos en la «Sacra Enfermería" de Malta, $y$, sobre todo, persiguiendo turcos y berberiscos en el Mediterráneo embarcados en la armada de galeras de la Orden de Malta, actividad que se conocía como "correr carabanas", es decir, perseguir a los cárabos o galeotes moros, y que hoy día se podria comparar con un servicio militar muy exigente.

Las campañas "corriendo carabanas" eran cuatro como mínimo, cada una de unos seis meses, y constituian, sin duda, una durísima, pero también, una magnífica formación militar y marinera para los caballeros. De hecho, hemos encontrado en muchos expedientes de marinos de guerra profesionales de la Armada española, que también eran caballeros de la Orden de San Juan, solicitudes de licencia del real servicio al monarca español para ir a Malta a "correr carabanas» ${ }^{19}$, interrumpiendo sus respectivas carreras, aunque sin perder antigüedad ${ }^{20}$.

Antes de ingresar en la Armada Arriaga corrió carabanas ${ }^{21}$ para la Orden, llegando a ser Bailío y Gran Cruz en la misma, lo que le supuso conseguir la titularidad de las encomiendas de León, Mayorga y Fuente la Peña, que le permitieron gozar de cuantiosas rentas, así como también de las rentas de otras encomiendas cuya titularidad no ostentó. Todos estos ingresos sumados a su sueldo de marino le permitieron vivir holgadamente, puesto que, muertos sus padres, pudo socorrer a cuatro de sus hermanas, cediéndoles de forma vitalicia algunas de estas rentas ${ }^{22}$, y esto ya en 1748, cuando siendo capitán de navío cedió a Ana María, Manuela y Joaquina una renta anual de 150 escudos que percibía del también caballero de la Orden D. Gonzalo de Adorno, Comendador de Beade ${ }^{23}$. Esto sucedía, por lo tanto, mucho antes de llegar a cobrar un sueldo importante, como fueron los 120.000 reales de vellón anuales que le correspondieron al convertirse en Secretario de

19 Archivo General de Simancas (A.G.S.). Secretaría de Marina, (SM). Sección Oficiales de Guerra, legs. 1 al 16 y ss. Muchos de estos legajos contienen listados de los oficiales de guerra de la Armada en tos que junto al nombre del oficial figura la anotación de "carabanas en Malta» o "con licencia en Malta".

20 Para saber más sobre la Orden de Malta consultar: C. MoRenés Y MARIÁtegul: Historia resumida de la Soberana Orden de Malta. Instituto Complutense de le Orden de Malta, Madrid, 1995; A. BLONDY: L'ordre de Malte au XVIIle siecle, des dernières splendeurs à la ruire, Paris, 2002. H. O'DONNELL Y DUQUE DE ESTRADA: "La Orden de Malta en las colecciones documentales del Museo Naval", $X$ Jornadas de Historia Maritima, Mayo, 1994, Cuadernos monográficos del Instituto de Historia y Cultura naval, $\mathrm{n} .{ }^{\circ} 23$, (1994). V. CÉSPEDES ARECHAGA: "Aportaciones inéditas a una historia común", Cuadernos monográficos del Instituto de Historia y Cultura Naval, n. ${ }^{\circ} 3$ (1994). J. Cervera PERY: "La Orden de Malta y la Armada: una vinculación histórica», Cuadernos monográficos del Instituto de Historia y Cultura Naval, $n .{ }^{\circ} 23$ (1994). A. Madrid y H. O'Donnell y Duque de Estrada: Actas del II Congreso de la Orden de San Juan, Instituto de Estudios Manchegos, 1999.

${ }_{21}$ F. DE P. PAvía: Galería biográfica de los generales de Marina, jefes y personajes notables que figuraron en la misma corporación de 1700 a 1868. 4 vols, Madrid, 1873, pp. 93-99.

a2 A María Teresa, viuda del vizconde de Palazuelos, le otorgó en 1756 poder para cobrar del Conde de Teba, Cardenal de la Iglesia Arzobispal de Toledo, una renta anual de 500 ducados de vellón que él disfrutaba; el mismo año a Ana Maria, Manuela y Joaquina, religiosas profesas del real convento de Santa Cruz de Valladolid y comendadoras de la Orden de Santiago, les otorgó poder para cobrar una renta de 200 ducados de la encomienda de Quiroga, y otra de 180 ducados de la de Puertomarín. Archivo Histórico de Protocolos Notariales de Madrid, (en adelante AHPNM), protocolos 17.256 y 17.261

23 AHPNM, protocolo 17.256. 
Marina e Indias en 1754, a lo que hay que sumar el sueido de teniente general, las propinas y demás emolumentos ${ }^{24}$.

Poco sabemos por el momento de esta primera etapa de educación, durante la cual no sólo se tuvo que gestar su vocación de marino, sino que debió adquirir una buena preparación náutica y militar navegando, primero como novicio y luego como caballero, en la escuadra de galeras de la Orden, persiguiendo corsarios en el Mediterráneo, puesto que en 1728 solicitó ingresar en el Cuerpo general de la Armada, que agrupaba a los oficiales de marina ${ }^{25}$, sin haber pasado previamente por la Academia de Guardias Marinas, creada en 1717 por Patiño para la formación de mandos. Efectivamente, Arriaga ingresó en la Armada el 6 de mayo de ese mismo año con el grado de Alférez de fragata ${ }^{26}$.

Arriaga dedicará a la marina de guerra, navegando en los navios de las distintas flotas, sus mejores años, sin dejar de navegar hasta su madurez, cuando, cumplidos los cincuenta, en 1751, fue nombrado Intendente de Cádiz y Presidente de la Casa de la Contratación, permaneciendo desde entonces definitivamente en tierra. Es altamente significativo que en la relación de bienes del expolio de sus pertenencias personales, llevado a cabo, como era preceptivo, por el recibidor de la Orden tras su muerte, se encontraran un ancla de hierro y dos cuadros de barcos ${ }^{27}$.

Su hermano Miguel ingresó en el Cuerpo de Granaderos y debió de permanecer largo tiempo en Malta al servicio de la Orden, como en el año 1733 testimonió el Gran Maestre de la misma:

«[... testificamos que el noble Don Miguel de Arriaga uno de los Frey caballeros de dicha nuestra casa del venerable priorato de Castilla y León, al presente está en vida y con perfecta salud, y reside aquí en Malta, al servicio de Dios y de nuestra Religión. Y por ser así la verdad por tanto y para que conste hemos mandado sellar las presentes con nuestro sello impreso en cera negra. Dadas en Malta en nuestro convento el día trece del mes de abril de mil setecientos treinta y tres... ${ }^{28}$

Durante este tiempo sin duda se granjeó la confianza de sus superiores, ya que, en 1756, se le concedió, mediante bula expedida en Malta y firmada por el Gran Maestre, el privilegio, que sólo tenian los caballeros profesos, de usar y llevar pendiente del cuello la cruz de oro y la del hábito, a pesar de estar casado. Al no

24 A.G.S. Sección Dirección General del Tesoro (en adelante DGT) Inventario. G. 23, legs. 46-47; A.H.N. Estado, leg. 3497; Archivo General de la Marina "Alvaro de Bazán" (en adelante AGMAB) Sección Secretaría, leg. 5021. J. A. Escudero: Los origenes del Consejo de Ministros en España. 2 vols, Madrid, 1979, pp. 251-256; G. FrANCO RuBIO: “Peformismo institucional y élites administrativas en la España del siglo XVIII: nuevos oficios, nueva burocracia. La Secretaría de Estado y del Despacho de Marina (1721-1808)" en J. L. CAstellanos, J. P. Dedieu y M. ${ }^{\star}$ V. López-Cordón (eds.), La pluma, la mitra y la espada. Estudios de Historia institucional en la Edad Moderna, Madrid, 2000, pp. 95-130.

25 D. Ozanam: La política exterior de España en tiempo de Felipe $V$ y de Fernando $V /$ en "Historia de España de Menéndez Pidal", Tomo XXIX, Madrid 1988, p. 477

26 AGMAB, Cuerpo General, leg. 620/86.

27 A.H.N., OO.MM., leg. 7.861.

${ }^{28}$ Copia de la carta del Gran Maestre autentificada notarialmente en A.H.N., OO.MM., exp. 664 
haber profesado en la Orden, como habia hecho su hermano Julián, pudo contraer matrimonio en 1748 con Ana María Parisani ${ }^{29}$, naciendo en Burgos en 1751 tanto su primogénito Miguel $^{30}$, Caballero de Santiago y oficial del regimiento de Guardias Españolas, como su hịa María Micaela. Ésta, en 1760, unos años después de la muerte de su padre, ocurrida en 1756, entró en el exclusivo colegio madrileño de la Visitación, que había sido fundado por la reina Bárbara de Braganza para la educación de las hijas de la nobleza ${ }^{31}$, de donde no salió, puesto que, terminada su etapa formativa, en 1770 profesó en la orden de las Salesas, encargadas del colegio, como monja de coro. Es más que probable que, como apunta Gloria Fran$\mathrm{co}^{32}$, la posición de su tío Julián, que en 1760 ya era Secretario de Estado de Marina e Indias, facilitara su ingreso en el colegio.

El hecho de que, el 30 de enero de 1776, una vez muerto Arriaga, su sucesor en la Secretaría de Marina, Pedro González de Castejón, concediera a Ana María Parisani, viuda de su hermano Miguel, una pensión en atención a los servicios prestados al rey por Julián ${ }^{33}$, es altamente significativo para valorar hasta dónde llegó la preocupación del bailío por el bienestar de su familia. Su hermano Miguel, que había fallecido el 14 de julio de 1756, había nombrado a Julián uno de sus albaceas testamentarios, y la viuda, Ana María Parisani, se trasladó a vivir a la Corte, donde permaneció el resto de su vida, como aseguraron los testigos que la conocieron y que fueron interrogados para el expediente de limpieza de sangre y probanza de nobleza de su hijo Miguel en 1778. Para asegurar el mantenimiento de la viuda e hijos de su hermano, Arriaga, en 1757, siendo ya secretario de Marina e Indias, consiguió que a Ana María Parisani se le concediera una pensión vitalicia de 100 doblones $^{34}$.

Por lo que respecta al hermano mayor, Cayetano, ya hemos mencionado que hizo carrera en la administración provincial como Regidor y Corregidor de varias ciudades, llegando a ser Intendente de la provincia de Palencia. Al no conseguir la Intendencia de la provincia de Burgos ${ }^{35}$, se retiró, permaneciendo como Alcalde perpetuo de su ciudad.

29 Parroquia de San Miguel de los Navarros de Zaragoza, libro de casamientos, año 1725, fol. 265 A.H.N., OO.MM. Exp. 664.

30 A.H.N., OO.MM. Exp. 664 y AGS, SG, leg. 5, expedientes 32 y 33.

31 G. Franco RuBIO: «Educación femenina y prosopografía: las alumnas del colegio de las Salesas Reales en el siglo XVıı", en Cuadernos de Historia Moderna, n. ${ }^{\circ} 19$ (monográfico) 1997, pp. $171-181$.

32 G. Franco Rubio: «Reformismo...», p. 123. Gloria Franco asegura que Micaela fue hija de Julián, pero éste permaneció soltero y no tuvo hijos legalmente reconocidos. Por el contrario, su hermano Miguel en su testamento la reconoce como hija suya, nombrándola junto a su otro hijo Miguel sus únicos herederos. A.H.N., OO.MM. leg. 644.

33 AGS, Secretaría y Superintendencia de Hacienda (en adelante SSH) leg. 53.

34 AGS, SSH, leg. 6, Aranjuez, 23 de Junio de 1757.

35 La intendencia de la provincia de Burgos con corregimiento fue concedida en 1763 a Alonso Pérez Delgado, oficial mayor de la Secretaría de Marina junto a Ensenada. Cuando Ensenada fue destituido en 1754 arrastró consigo a sus más directos colaboradores. En 1760 Carlos III los rehabilitó parcialmente otorgándoles cargos administrativos pero manteniéndoles alejados del poder. A.H.N., Consejos, leg. 13.594. 
Como primogénito habia heredado los mayorazgos familiares de Hinojosa, Vera y Rivera. Además, su madre, María Rivera, le había favorecido en su testamento con una mejora del tercio y quinto para aumentar las rentas de dichos mayorazgos, que sin embargo debieron procurarle no pocos dolores de cabeza a la vista del prolongado pleito que emprendió en 1751 contra sus tíos y primos maternos por su reparto ${ }^{36}$. Cayetano murió en 1778 sin verlo resuelto, heredando los mayorazgos su hijo Joaquín de Arriaga y Salamanca y su sobrino Miguel de Arriaga y Parisani.

Muchos años después de su muerte, en 1806, Camila Arriaga y Recalde, hija natural de Joaquin, solicitará judicialmente suceder a su difunto padre en los mayorazgos familiares ${ }^{37}$; Cayetano nunca habia aprobado la relación de su hijo con María Ignacia Recalde ${ }^{38}$ por no ser ésta del mismo rango social, llegando incluso a solicitar en repetidas ocasiones a través de la Chancillería de Valladolid ${ }^{39}$ la persecución y encarcelamiento de Joaquín basándose en su prerrogativa como pater familias de negarse a dar su consentimiento al matrimonio.

Hechos como éste eran habituales, sobre todo teniendo en cuenta las estrategias matrimoniales que se desplegaban a la hora de la selección para evitar matrimonios de inferior rango o patrimonio, y especialmente en el caso que nos ocupa por tratarse del primogénito ${ }^{40}$. La marginación social e incluso jurídica de los hijos naturales, como la que sufrió Camila, también fue habitual. Camila tuvo que pleitear, tanto para conseguir ser reconocida judicialmente como hija natural por la Chancillería de Valladolid, como para tener derecho a una renta anual en concepto de alimentos ejecutorios, que tras la muerte de su padre el 27 de diciembre de 1799 dejó de percibir por decisión de su tío el Marqués de Albareal, casado con la única hermana de su padre. Ana María, y convertido en administrador de la herencia que comprendía los mayorazgos.

En cualquier caso, y sin necesidad de incurrir en un análisis profundo de las características estructurales familiares del siglo XVIII, que no es el caso, destacaremos tan sólo algunos hechos relevantes, típicos de los comportamientos del Antiguo Régimen que hemos encontrado en la familia Arriaga: el que el grueso del patrimonio familiar pasara al primogénito, destinando al resto de los hijos tan sólo una parte de éste, que en su mayor proporción se invertia en dotar a las hijas; o el que los hijos segundones se dedicaran a la iglesia y al ejército; o que la mayoría de las hijas profesaran en alguna Orden religiosa; o que una serie de cargos relevantes de la administración provincial permanecieran en manos de la familia a tra-

${ }^{36}$ A.H.N., Consejos, leg. 24.263-18.

${ }^{37}$ A.H.N., Consejos, leg. 29.442.

${ }^{38}$ Historia de Camila Arriaga y Recalde en Biblioteca Central de la Armada, Ms., 929-V.8-270.

39 Un tío suyo, Pedro Jacinto de Arriaga y San Martín, había sido Alcalde de Hijosdalgo en la Chancillería vallisoletana, por lo que, teniendo en cuenta que parte de la familia era de Valiadolid, no le faltaron apoyos para conseguir encarcelar a Joaquin durante muchos años, mientras que Ignacia y Camila se refugiaron en Francia

${ }^{40}$ G. Franco RublO: La vida cotidiana en tiempos de Carlos III, Madrid, 2001, pp.17-45. 
vés de los primogénitos de varias generaciones; o que los hijos abandonaran el hogar paterno siendo aún niños para ingresar en las instituciones religiosas o militares en las que permanecerán el resto de sus vidas...

Vemos, pues, que todos los hechos enumerados encajan perfectamente en las características que se adscriben al prototipo de una familia de hidalgos provinciales de su época, que coincide con el final de Antiguo Régimen, preocupada por mantener y aumentar tanto su prestigio social como su patrimonio. En este sentido Julián personalizará con creces todas las aspiraciones familiares, reflejando su trayectoria profesional la tradicional política de Austrias y Borbones de premiar, con nombramientos y mercedes, servicios y contribuciones hechas al Real Servicio o a la Nación por miembros de la administración del Estado.

Carlos III culminará esta trayectoria promulgando varias resoluciones al respecto y creando la Real Orden de Carlos $1 \mathrm{II}^{41}$, pero al bailío, pese a mantenerlo como ministro hasta su muerte, ocurrida en 1776 , no le concedió ningún título nobiliario, como sí hizo con la mayoría de los ministros que le sivieron e incluso con otros marinos. Además, esperó hasta 1771 para nombrarle Consejero de Estado, dejando pasar ocasiones como cuando en 1764 nombró Consejeros de Estado a todos los ministros en ejercicio excepto a él, para hacerle ver que no estaba demasiado contento con su trabajo, como indicó en sus despachos al canciller Kaunitz el embajador austriaco en la corte madrileña, conde Rosenberg. La reacción de Arriaga fue recurrir al disimulo, ya que en ningún momento de su larga carrera se planteó presentar su dimisión ${ }^{42}$.

\section{BIOGRAFIA PROFESIONAL DEL MARINO JULIÁN DE ARRIAGA Y RIBERA}

De su infancia y primera adolescencia, coincidentes en el tiempo con la Guerra de Sucesión, no sabemos nada. Arriaga abandonó definitivamente el domicilio familiar de Burgos en 1717, con diez y siete años, para dirigirse a Malta, sede de la Orden de San Juan de Jerusalén, con el fin de convertirse en caballero de la misma, siguiendo una tradición familiar. Tras permanecer un año en el convento de

41 G. ANES: “Sociedad y Economia” en Actas del Congreso internacional sobre Carlos /I/ y la /lustración, Madrid, 1989, tomo II, pp. 1-12

${ }^{42}$ H. JURETSCHKE: Berichte der diplomatischen Vertreter des Wiener Hofes in der Zeit Carl III. (17591788), Madrid 1971, tomo III, p., 33. Rossenberg a Kaunitz, Madrid, 27 febrero 1764 “[...] Der König hat alle seine Staats-Secretarien su Staatsräten ernennt, allein den Arriaga ausgenommen, welches in der Absicht geschehen, um ihm zu erkennen zu geben, dass er mit dessen bisherigen Betrag nicht wohl zufrieden sei. Arriaga dissimulieret bis nunzu und scheinet nicht gesinnet zu sein, seine Entlassung zu verlangen, welche ihm der König selbst gegeben würde, wenn ihm nicht ein besseres Subjectum zu finden schwer fallete». "El rey ha nombrado Consejeros de Estado a todos sus Secretarios de Estado con la única excepción de Arriaga, al parecer con la intención de manifestarle su descontento con sus aportaciones realizadas hasta ahora. Arriaga disimula todo lo que puede y no parece tener la intención de presentar su dimisión, que el propio rey le pediria si no le resultara dificil encontrar un sujeto mejor". (Traducción propia). 
la Orden como novicio, profesó los votos de pobreza, obediencia y castidad, convirtiéndose en caballero de justicia, que equivalía al estado de un religioso profeso. Con el fin de conseguir alguna encomienda, siguió el cursus honorum establecido para los caballeros de justicia, "corriendo carabanas", es decir, participando en un mínimo de cuatro campañas marítimas de seis meses en el Mediterráneo, navegando a bordo de la escuadra de galeras de la Orden, haciendo el corso contra los berberiscos.

Gracias a esta formación militar y marinera, en 1728 pudo ingresar en el Cuerpo General de la Armada como alférez de fragata ${ }^{43}$, iniciando su carrera de marino de guerra en la recién creada Armada Real de Felipe $V^{44}$. El primer embarque del que tenemos constancia lo realiza en uno de los tres navios de la escuadra de guerra que, al mando del marqués de Marí, convoyaron la flota mercante de Indias que salió de Cádiz en octubre de 1729 con destino a Veracruz ${ }^{45}$.

El viaje de regreso lo realizó en el Santa Isabe ${ }^{46}$, llegando a Cádiz en junio de 1730, puesto que desde el 20 de julio está destinado como oficial de órdenes en El Gallo, uno de los navíos de la flota de Azogues que comandaba Rodrigo Torres con destino al virreinato de Nueva España ${ }^{47}$. Esta flota sufrió un dramático naufragio en el Caribe a causa de un huracán, y Arriaga como oficial de órdenes tuvo un destacado papel en las operaciones de auxilio. Su buen comportamiento le valió una carta de recomendación del virrey de Nueva España, marqués de Casafuerte $^{48}$, que muy probablemente fuese la causa de su inmediato ascenso a alférez de navio ${ }^{49}$. Como tal y ejerciendo nuevamente de oficial de órdenes hizo el viaje de regreso a Cádiz, donde desembarcó en julio de $1731^{50}$.

Apenas desembarcado es destinado a servir en La Reina, uno de los navios que componían la flota compuesta por tres escuadras que, al mando del marqués de Marí, debía llevar a Italia a Carlos de Borbón para tomar posesión de los du-

${ }^{43}$ AGS, SM, leg. 766. En el registro de patentes concedidas en 1728, consta la concedida a Julián de Arriaga y Rivera como alférez de fragata.

44 AGMAB, leg. 620/86, En la hoja de servicios de Arriaga corista que fue alférez de fragata desde el 6 de mayo de 1728.

45 F. DE Paula Pavia: Galería biográfica..., t, 1, p. 93.

46 AGMAB, Oficiales de Guerra, Cádiz, (OO.G.C.) leg. 2849. Arriaga consta embarcado en el Santa Isabel, uno de los navíos de la escuadra del marqués de Marí, con un sueido de 20 escudos mensuales.

47 Ibidem. Los navios de la flota de Azogues eran El Gallo, que iba como capitana de la flota, en el que embarcó Arriaga, y el San Juan, además de un bergantín que iba como patache para regresar a España con la noticia del arribo de la flota a Veracruz. En los libros de contaduría de los oficiales de guerra adscritos al departamento de Cádiz figura que su sueldo fue de 25 escudos al mes, y que se cargaron en la cuenta del alférez de fragata Julián de Arriaga 2.770 reales de vellón y 5 maravedís por los géneros que para su uniforme habia tomado de unos mercaderes gaditanos.

48 AGS, SM, leg. 2, doc. 131, México, 2 de febrero de 1731. Carta de recomendación del marqués de Casafuerte, virrey de Nueva España a José Patiño.

49 AGS, SM, leg. 2, doc. 27. En la propuesta formal de ascensos que se adjuntaba a $S$. $M$. junto con las patentes de los cargos para su rúbrica, figura el nombre de Arriaga para ser promovido de alférez de fragata a alférez de navio. AGMAB, leg. 620/86. En su hoja de servicios consta que fue ascendido a altérez de navio el 10 de febrero de 1731 .

50 AGMAB, OO.G.C. leg. 2849. 
cados de Parma y Plasencia. La campaña se desarrolló sin incidentes, pudiendo desembarcar Arriaga del navío La Reina, una vez finalizada ésta, en Cádiz, el 22 de enero de $1732^{51}$.

Mientras disfrutaba una licencia de tres meses (desde enero hasta marzo de 1732), concedida por Patiño ${ }^{52}$, fue ascendido a teniente de fragata ${ }^{53}$, y transcurrido este tiempo, por algún motivo que desconocemos, no se reincorporó a su destino en el departamento de Cádiz en la fecha prevista. El retrasó quedó constatado en el departamento de Cádiz: "[...] vino de licencia concedida por S. M. el 31 de diciembre de 1731 por tres meses y una vez cumplida no se ha presentado ${ }^{54}$.

No debió tener trascendencia este retraso pues unos meses después fue destinado al Rubi. Francisco de Paula Pavía, en su Galería biográfica de los generales de Marina..., le atribuye haber participado con este navío en la campaña de la reconquista de Orán, que finalizó en diciembre de 1732, dato que incluyen hasta hoy mismo todos los autores que dedican algunas líneas a la biografía de Arriaga. Por el momento no hemos encontrado pruebas concluyentes que avalen este hecho, pero sí nos encontramos a Arriaga embarcado en el Rubi, capitana de la flota de Indias que, al mando de Rodrigo Torres, había salido de Cádiz en agosto de 1732 hacia Veracruz, iniciando el viaje de regreso a Cádiz en julio de $1733^{55}$. Como, evidentemente no pudo estar en ambos sitios a la vez, quizá una vez desembarcado de la campaña de Orán, en diciembre de 1732, podría haber llegado a América en un aviso en los primeros meses de 1733, incorporándose a la flota de Torres para realizar el tornaviaje, ya que hasta septiembre de 1733 no zarpó la flota de Azogues, que fue la única que salió ese año, por lo que, si no fue en un aviso es imposible que se hubiera podido incorporar a la flota de Indias que comandaba Rodrigo Torres para realizar el viaje de regreso ${ }^{56}$. Nosotros creemos que no participó en la campaña de Orán, sino que partió con Torres en el Rubí hacia Nueva España en agosto de 1732, lo que explica que aparezca registrado como embarcado en el Rubi ya en enero de 1733.

51 Ibidem

52 lbídem, Sevilla, 31 de diciembre de 1731. Despacho de Patiño ccncediendo licencia por tres meses a Arriaga. AGMAB, leg. 620/86, Sevilla, 11 de junio de 1732. Carta de Patiño a Salvador de Olivares, titular de la contaduría del departamento de Cádiz, confirmándole tanto la concesión de la licencia como el permiso para que se le abonara el sueldo de los tres meses que habia estado con licencia del real servicio.

${ }_{53}$ AGMAB, C.G. leg. 620/86. Patente de teniente de fragata en AGS, SM, leg. 754, folio 82.

54 AGS, SM, leg. 2, exp. 64.

55 Archivo Museo Naval (MN), manuscrito (Ms) 1991. "Listado de oficiales sueltos que sirven en la Real Armada, enero 1733-1735», folio 346: «teniente de fragata Julián de Arriaga, sirviendo su empleo en el Rubí con 30 escudos de vellón de sueldo al mes". Ibidem, folio 140: "embarcado en el Rubi, capitana de la flota que pasó a Nueva España al mando de Torres. Presentóse en Cádiz el 30 de diciembre de 1733, enviado por Torres para avisar de la pérdida de la flota. Patiño ordenó se restituyera a La Habana para regresar en uno de los cuatro navíos fletados para traer el tesoro rescatado a España. Llegó en el Europa a Cádiz el 19 de junio de 1734, pasando destinado al San Fernando el 3 de julio para pasar a comandar la fragata San Estaban el 30 de agosto de 1734 ".

56 Según G. Walter, en 1733 sólo salieron dos avisos y se dirigieron a Cartagena de Indias: uno llevaba un cargamento de vino y el otro de productos desconocidos. G. WALkeR: Política española y comercio cclonial, 1,700-1789, Barcelona, 1979, apéndice I, cuadro 4: “Navios de aviso, 1700-1740". 
De lo que no hay duda es que, a los dos días de haber salido de La Habana la flota de Torres para iniciar el viaje de vuelta, el 15 de julio de 1733, naufragó en la boca del canal de Bahamas ${ }^{57}$, y entre los más de diez y seis barcos que se perdieron, estaba El Rubi ${ }^{58}$. Al mes siguiente del naufragio, en agosto, Arriaga fue ascendido a teniente de naví ${ }^{59}$, y en junio de 1734 , casi un año después de haber naufragado, los supervivientes de la flota junto con el tesoro rescatado, finalmente, consiguieron llegar a Cádiz en cuatro navios fletados por la Real Hacienda, conducidos por Rodrigo Torres, quien, una vez en la Corte, escribió a Patiño recomendándole a Arriaga ${ }^{60}$.

Esta nueva recomendación tuvo el efecto de que Patiño inmediatamente le entregara el mando de una fragata, la San Esteban, para pasar a Barcelona ${ }^{61}$, donde debía hacerse cargo de un convoy compuesto por catorce embarcaciones para transportar tropas y vestuario a Nápoles. Desde la fragata San Esteban, Arriaga confirmó a Patiño su llegada a Barcelona ${ }^{62}$.

El comisario ordenador de la Marina, Cenón de Somodevilla, era el organizador de toda la intendencia de la Marina durante las campañas italianas iniciadas en 1733 para conquistar los territorios italianos para Carlos y Felipe de Borbón. Una vez que se recuperó el reino de Nápoles, Don Cenón informaba puntualmente desde Mesina al ministro Patiño de todo lo relativo a la escuadra del Mediterráneo, cuya principal misión era convoyar el trasporte de tropas y pertrechos a Italia. Este contexto posibilitó que Arriaga, comandante de la fragata San Esteban, una de las pertenecientes a la escuadra del Mediterrárieo, y Somodevilla entablaran una relación decisiva para la carrera del primero. Hasta agosto de 1735 Arriaga, al mando de la San Esteban, realizó operaciones de transporte entre España e Italia ${ }^{63}$.

Ese mismo mes es destinado al San Fernando ${ }^{64}$, aunque hasta septiembre no desembarcará de la San Esteban, y por enfermedad no se pudo presentar a la re-

57 AGS, SM, leg. 493, México, 18 de agosto de 1733. Carta del virrey de Nueva España, marqués de Casafuerte a Patin̄o. G. Walker cita este naufragio, en el que se perdieron muchas vidas, navios y dinero. G. J. Walker: Politica española..., pp. 237-238.

58 Detallado informe de Torres sobre el naufragio transcrito en A. Garcia-BaQUERo Gonzáez: Cádiz y el Atlántico, 1717-1778, Cádiz, 1988, tomo 1, pp. 384-390.

59 AGMAB, OO.G.C., leg. 2849 y C.G., leg. $620 / 86$.

60 AGS, SM, leg. 2, exp. 138, San lldefonso, 28 de julio de 1734. Rodrigo Torres a Patiño: "[...] en cumplimiento de mi obligación no puedo menos de hacer presente a V. E. la especialidad con que en mi naufragio de la flota se esmeraron en el cumplimierito de su obligación el teniente de navio $D$. Julián de Arriaga y el altérez de navío D. José de San Vicente [...] El primero habiendo atendido a cuantas providencias por mi se daban en su exacta ejecución, con tan buena conducta que era quien en mi nombre las firmaba todas por no podierlo yo hacer a causa de mi indisposición...".

61 AGS, SM, leg. 431, San Ildefonso 23 de agosto de 1734. En la comunicación del nombramiento que desde la secretaría de Marina se hizo al comandante del departamento de Cádiz, Blas de Lezo, se ha tachado el nombre del capitán a quien en principio se había encomendado el mando de la fragata San Esteban, Félix Celorán, sustituyéndolo por el de Arriaga, a quien se nombra además comandante de la misma.

62 AGS, SM, leg. 431, Arriaga a Patiño, Barcelona, 25 de septiembre de 1734: "[...] el dia 23 de este di sondo en esta rada, a los 15 dias de mi salida de Cádiz...".

63 AGS, SM, leg. 432-1, Isla de León, 7 de agosto de 1735. Rodrigo Torres, comandante del departamento de Cádiz avisa a Patiño el arribo de la fragata San Esteban y su convoy de 15 embarcaciones.

64 AGS, SM, leg. 3, exp. 77. 
vista que debería haber pasado el quince de septiembre, haciéndolo el quince de octubre ${ }^{65}$. Como fuere, ese año se quedó sin destino y sin ascenso, y presumiendo que contaba con el apoyo del secretario de Marina, Patiño, a quien hasta ahora debía sus ascensos, se atrevió a escribirle pidiéndole una nueva promoción ${ }^{66}$. Sin embargo, ni fue ascendido, ni recibió un nuevo destino por lo que, en febrero de 1736 escribió nuevamente a Patiño pidiéndole licencia de seis meses para pasar a la Corte ${ }^{67}$, que sí se le concedió.

Arriaga, previa solicitud al ministro Patiño, consiguió prorrogar la licencia durante quince meses, como otros muchos oficiales en esta época en la que, "había pocos armamentos previstos", lo que es cierto pues sólo salieron dos flotas de Azogues, una septiembre de 1736 y otra en diciembre de $1737^{68}$. En junio de 1737, fallecido ya Patiño, solicitó a su sucesor en la secretaría de Marina, el marqués de Torrenueva, que se le abonaran los sueldos correspondientes a los quince meses que llevaba disfrutando de licencia del real servicio ${ }^{69}$. La Secretaria denegó la solicitud remitiéndolo al Almirantazgo, del que Ensenada era secretario. El primer impulso que éste, desde su nuevo puesto, dio a la carrera de Arriaga fue el ansiado ascenso a capitán de fragata en agosto de ese año ${ }^{70}$, además de concederle una nueva licencia del real servicio de ocho meses a partir de septiembre ${ }^{71}$.

No hay duda de que Arriaga aprovechó el tiempo que permaneció en la Corte, en el entorno de Ensenada, para integrarse en el círculo de los que componían su red política, es decir para convertirse en hechura de quien con gran talento había conseguido, de momento, controlar los asuntos de la Marina, en un primer paso hasta convertirse en ministro todopoderoso. La confianza que inspira el saberse cercano al poder por derecho propio, permitió a Arriaga pedir con toda naturalidad un favor a Ensenada, asegurándole al tiempo su lealtad:

«[...] Madrid, hoy sábado: mi amigo y Sr. sirva esta de hacer a VM memoria de la licencia de Blanes...quédeseme VM confiado pues soy todo de VM, ya lo sabe y para hablar de las desgracias de nuestro bordo no hay valor que le haya dado el cielo y a VM me guarde muchos años. De VM de corazón»"72.

Al mes siguiente solicitó oficialmente al Almirantazgo que se le abonasen todos los sueldos que había dejado de percibir durante los dos años que llevaba con licencia del real servicio, que anteriormente le habian sido denegados por la Secretaría de Marina. La poderosa mano de su benefactor ahora se lo concedió.

\footnotetext{
65 AGMAB, OO.G.C., leg. 2850.

66 AGS, SM, leg. 3, exp. 68. Arriaga a Patiño, Cádiz, 27 de agosto de 1735.

67 AGS, SM, leg. 3, exp. 175. Arriaga a Patiño, Cádiz 6 de febrero de 1736. AGMAB, leg. 2850.

68 A. Garcia-Baquero: Cádiz y..., tomo I, pp. 278-279. G. Walker: Política española..., apéndice I, cuadro 2: "Flotas de mercantes y azogues. 1700-1740".

${ }^{69}$ AGS, SM, leg. 4, exp, 206. Carta del 27 de julio de 1737 de Arriaga al marqués de Torrenueva.

${ }^{70}$ AGS, SM, leg. 4, exp. 34 y leg. 756, folio 55. Patente de capitán de fragata concedida el 19 de agosto de 1737

71 AGMAB, OO.G.C., leg. 2.850.

72 AGS, SM, leg. 5, exp. 65, 11 de marzo de 1738. Minuta de Arriaga a Ensenada solicitando prórroga de una licencia concedida a Manuel de Blanes.
} 
En mayo de 1738, concluida la licencia, se reincorpora al departamento de Cádiz, donde se le entrega el mando del Nueva España y permanece a la espera de un nuevo armamento. Una vez más esta gracia vendrá de la mano del marqués de la Ensenada, quien saltándose al capitán más antiguo "por su salud" propondrá a Arriaga para ir a Buenos Aires como segundo del capitán designado para hacerse cargo de los navíos de aquel puerto, que se hallaban sin comandante para poder regresar a España por problemas disciplinarios de éste. A Arriaga se le encomendó el mando de una de las fragatas que debían regresar de Buenos Aires a Cá$\mathrm{diz}^{73}$. Los preparativos para este armamento destinado a Buenos Aires se prolongaron, y en el ínterin la Secretaria de Marina decidía enviar a Nueva España la flota de Indias, que no había salido en 1738 , solicitando al Almirantazgo propuestas para las tripulaciones ${ }^{74}$. Ensenada no dudó en recurrir a los suyos, proponiendo como comandante de la flota al jefe de escuadra José Pizarro y como capitán de la capitana a Arriaga, a quien retiró del proyectado armamento a Buenos Aires.

Al no poder llegar a tiempo Pizarro para hacerse cargo del mando de la flota, que tenia prevista su salida en agosto de 1739 , fue sustituido por el conde de Clavijo, para quien Arriaga no era santo de su devoción, por lo que intentó que Ensenada nombrara otro capitán de pabellón:

«[...] No duda VS pues comprende el nuestro, con cuanta más satisfacción se embarca un comandante llevando un capitán de pabellón que sea de su mayor satisfacción... Merezca yo a VS se empeñe un que se me conceda esta gracia y en el caso de no poder suceder, que no se me nombre ningún inútil porque es absolutamente contra el servicio del Reys ${ }^{75}$.

La contundente respuesta de Ensenada no dejaba lugar a dudar de su autoridad, ni de la firmeza con que estaba dispuesto a defender a los miembros de su red:

"[...] Estando ya nombrado el capitán de fragata D. Julián de Arriaga para que lo sea de pabellón en la misma flota, y ser éste oficial en quien concurren todas cuantas circunstancias son necesarios para ejercer este empleo, no tiene por conveniente se remueva su destino " ${ }^{76}$.

Todas las propuestas sobre nombramientos hechas por Ensenada fueron aceptadas por la Secretaría de Marina ${ }^{77}$, pero los preparativos para el despacho de la flota se complicaron y retrasaron al tener que trasladar en ella al nuevo virrey de

${ }^{73}$ AGS, SM, leg. 780. Carta de Ensenada a la Secretaría de Marina con la propuesta, Madrid, 4 de diciembre de 1738 y carta de la Secretaría de Marina aceptando la propuesta de Ensenada del 18 de diciembre de 1738

${ }^{14}$ lbidem, Buen Retiro, 18 de mayo de 1739. Carta de la Secretaria de Marina al Almirantazgo.

75 AGS, SM, leg. 397-1, doc. 51, Vaidepeñas, 13 de junio de 1739. Conde de Clavijo a Ensenada.

76 Ibidem, doc. 52, Madrid, 23 de junio de 1739. Ensenada al conde de Clavijo

77 AGS, SM, leg. 780. Carta de la Secretaría de Marina al Almirantazgo del 22 de mayo de 1739. 
Nueva España, a su numeroso séquito y su aún más numeroso equipaje. La declaración de guerra de Inglaterra en octubre de 1739 hizo que se suspendiera la salida de la flota hacia Veracruz y que en su lugar se empezaran, con bastante prisa, los preparativos para enviar a La Habana una escuadra de guerra de doce navíos que, al mando del teniente general Rodrigo Torres, debía reforzar la defensa del Caribe.

Arriaga, al mando del Nueva España de sesenta cañones, fue destinado a esta escuadra, que salió de Ferrol en julio de 1740, siendo posteriormente engrosada por todos los navíos de guerra disponibles de la flota de Barlovento en Cartagena de Indias, así como por los de La Habana y Veracruz, y que, a pesar de su inferioridad frente a la inglesa, patrullando constantemente las aguas caribeñas, consiguió contener la creciente agresividad británica en la región. Torres, en un tono coloquial, enviaba continuos informes de cuanto acontecía a su superior y amigo Ensenada, y como es natural también le hablaba de los oficiales a su cargo:

«[...] Los demás capitanes de mi escuadra son muy buenos aunque algunos más sobresalientes como Chatelain, San Just, Arriaga, Antaio, Marroquín, Dn. Daniel, Orozco, Varela, Cerda y Gerbaut» ${ }^{78}$.

A finales de 1744 Rodrigo Torres fue relevado en el mando de la escuadra por Andrés Reggio y junto con algunos de sus capitanes emprendió el regreso a Ferrol, trayendo repartidos entre los distintos navíos que le acompañaban el tesoro de La Habana. Arriaga le acompañaba al mando del Brillante, con el que entró en el puerto de Ferrol el diez de enero de 1745, quedando destinado en ese departamento al mando del Europa hasta septiembre de 1747 en que fue llamado a la Corte por Ensenada ${ }^{79}$.

Las buenas palabras de Torres fueron decisivas para que, en la promoción de oficiales llevada a cabo en junio de 1745, los capitanes de fragata Varela, de la Cerda, Gerbaut, Orozco y Arriaga fueran ascendidos a capitanes de navío ${ }^{80}$.

Arriaga permaneció en la Corte un año largo, en el entorno inmediato de su mentor, convertido ya en todopoderoso ministro de Fernando VI. La firma del Tratado de Aquisgrán en 1748 permitió a España dedicar nuevamente más atención a combatir el corso berberisco en el Mediterráneo. Para ello se destinó una escuadra compuesta por dos navíos y cuatro jabeques mallorquines cuyo mando se entregó

${ }^{78}$ AGS, SM, ieg. 398-2, folio 689. Torres a Ensenada, La Habana, 12 de abril de 1741 , a bordo del $/ n$ vencible.

79 AGS, SM, leg. 399-2, En el extracto de las revistas de oficiales efectuadas en enero de 1745 en La Corur̃a, Arriaga figura al mando del navio Europa. AGS, SM, leg. 13-1, exp. 67. En la relación de oficiales destinados en el departamento del Ferrol realizada el 16 de junio de 1747 Arriaga figura entre los capitanes de navio al mando del Europa. Ibídem, exp. 6, minuta del 15 de septiembre de 1747: "A D. Julián de Arriagá se le llamó a la Corte para fines de servicio al Rey, y se le dieron las órdenes a Cosme Álvarez y a Bernardino Freyre".

AC AGS, SM, leg. 12-1, exp. 21 y exp. 79. AGMAB, leg. 2850 , folio 69 . Consta que ganaba 85 escudos al mes. AGS, SM, leg. 758, folio, 23, Patente de capitán de navio expedida en junio de 1745. 
en noviembre a Arriaga ${ }^{81}$, quien en esta ocasión no tuvo ni que solicitar formalmente que se le pagara el sueldo de los meses que habia estado en Madrid. Desde la Secretaría de Marina el mismo día que se notificaba oficialmente el nombramiento, se pedía, tanto al intendente de Ferrol, Cosme Álvarez, como al ministro contador, Bernardino Freyre, que pasasen aviso a la contaduría de Cartagena para que alli se le abonase el sueldo correspondiente al tiempo que Arriaga habia estado en la Corte dedicado al real servicio ${ }^{82}$.

En septiembre de 1749, casi solapándose con el final de la campaña de corso, se le comunicó oficialmente el ascenso a jefe de escuadra y se le encomendó el mando de una expedición de guerra especial, destinada a sofocar la rebelión de la ciudad de Caracas contra la Compañia Guipuzcoana ${ }^{83}$. También se le premió económicamente concediéndosele una ayuda de costa o gratificación de 120.000 reales de vellón "en atención a los gastos extraordinarios que ha tenido en la campaña que acaba de hacer en el Mediterráneo y a los que ahora se aumentan en el viaje y expedición a Caracas" ${ }^{84}$. Es evidente que Ensenada estaba contento con el resultado de la larga y agresiva campaña de corso llevada a cabo por Arriaga, de lo contrario ni le hubiera encomendado una misión tan delicada como la caraqueña, ni le hubiera colmado de gracias.

No obstante, Ensenada era consciente de que este, más que evidente, trato de favor a Arriaga podría provocar muchas envidias y protestas justificadas, por lo que le pidió expresamente que mantuviera secreto el nombramiento en España:

"[...] Atendiendo el Rey a los méritos de VS se ha servido promoverle a jefe de escuadra de su Real Armada, cuya noticia doy a VS con mucho gusto mio, dirigiéndole la Patente que no presentará VS en Cádiz para que se tome razón de ella, por ser conveniente que ahora no se sepa alií de esta gracia... Tampoco publicará VS el ascenso en ese puerto ni en los mares de España, pero si en los de América.... ${ }^{85}$

El reconocimiento y agradecimiento de Arriaga no se hizo esperar. No era para menos:

"[...] la especial nueva honra que el rey me confiere en el ascenso a jefe de escuadra, cuya Patente me remite VE con cu carta del 27 de este, me deja con el re-

81 AGS, SM, leg. 13-2, exp. 150; 13 de noviembre de 1748. «[...] Al capitán de navío Julián de Arriaga se le concedió el mando de los nombrados América y Constante destinados al corso en el Mediterráneo, y mandó socorrer con 96 reales a cuenta de la gratificación de mesa".

82 Ibidem, doc. 228. Aviso al departamento de Ferrol del 13 de noviembre de 1748.

83 AGS, SM, leg. 14-1, exp. 5. Buen Retiro, 27 de septiembre de 1749. Notificación del ascenso a jefe de escliadra adjuntándole la patente. AGS, SM, leg. 758 , folio 116 . Patente de jefe de escuadra concedida el 27 de septiembre de 1749.

84 AGS, SM, leg. 14-1, exp. 111, Cartagena, 16 de septiembre de 1749. AGS, SM, leg. 401-1, doc., 278, Cartagena, 3 de septiembre de 1749, Arriaga a Ensenada confirmando haber recibido la orden para la expedición a Caracas al mando de los navios América y Constante además de otros fletados para la ocasión.

${ }_{85}$ AGS, SM, leg. 14-1, exp. 5, Madrid, 27 septiembre de 1749. Ensenada a Arriaga en minuta aparte adjuntada a la notificación oficial del ascenso. 
conocimiento que pide tan real benignidad, y como que me conozco poco acreedor, anhelo merecer en lo sucesivo corresponder a éste anticipado premio. $Y$ bien persuadido a que en su logro soy de donde me previene deudor a el inflijo de VE, le doy las más atentas gracias, y quisiera mostrarme digna hechura suya. Observaré el sigilo que VE me manda y el publicarlo" ${ }^{86}$.

Mucha confianza y mucho agradecimiento debía sentir el marqués de la Ensenada hacia Arriaga como para entregarle consecutivamente el mando de dos expediciones especiales y de máxima confianza. Además, teniendo en cuenta que en este caso sí le importaba, y mucho, tener que enfrentarse a críticas y quejas justificadas. Mientras Arriaga supervisaba la puesta a punto de los navíos América y Constante en Cartagena, al marqués de la Victoria, director del departamento marítimo de Cádiz, se le encomendaba el fletamento y armamento de cuatro fragatas para transportar dos regimientos de tropa a Venezuela. Los preparativos se hicieron en apenas mes y medio pues Arriaga zarpó de Cádiz con tropas y pertrechos para el astillero de La Habana el 2 de octubre. En noviembre llegó a La Guaira tomando inmediatamente posesión del mando de la plaza ${ }^{87}$. En enero confirmaba a Ensenada el regreso a Cádiz de los navíos América y Constante, permaneciendo él en Caracas con el objetivo de sofocar la rebelićn ${ }^{88}$.

Arriaga actuó en Caracas en calidad de gobernador y capitán general con mando interino, para lo cual se le proveyó de las correspondientes instrucciones, garantizándosele mediante una Real Cédula libertad total de acción ${ }^{89}$. Su papel no fue fácil, pero supo negociar prudentemente con los alzados evitando confrontaciones y consiguiendo una momentánea pacificación ${ }^{90}$. De hecho, a su regreso a España advirtió al marqués de la Ensenada de un posible rebrote de la insurrección por el descontento del estamento dirigente, al encontrarse encarcelados algunos de sus miembros que además eran aristócratas (como así ocurrió). En la sociedad estamental del Antiguo Régimen la nobleza era intocable, idea que compartía Arriaga independientemente de la culpabilidad de los rebeldes $^{91}$.

En marzo de 1751 se accedió a su petición de regresar a España cumplida su misión de pacificador, concediéndosele permiso para la vuelta una vez hubiese traspasado el mando a su sucesor Felipe Ricardos, hasta entonces gobernador de Málaga. Llegó finalmente a Cádiz en octubre, en un navío holandés fletado por la Real Hacienda, realizando la que sería su última navegación. En Cádiz, el intendente general de la Marina del departamento, el anciano Francisco de Varas, le estaba esperando con la orden de Ensenada de presentarse inmediatamente en la Corte. Arriaga llegó al Escorial en octubre de 1751 pasando a integrarse en la Jun-

86 Ibidem, Cartagena, 1 de octubre de 1749. Arriaga a Ensenada.

${ }^{87}$ AGI, Caracas, leg. 57. El testimonio de toma de posesión tiene fecha de 1 de diciembre de 1749.

${ }_{88}$ AGS, SM, leg. 401-2, doc. 513, Caracas, 13 de enero de 1750. Arriaga a Ensenada.

s9 AGI, Caracas, leg. 56, Real Cédula, Buen Retiro, 15 de septiembre de 1749

90 F. MORAles Padrón, Rebelión contra la Compañia de Caracas, Sevilla, 1955, pp. 91-110.

9) AGI, Caracas, leg. 321. Arriaga a Ensenada, Madrid, 7 de diciembre de 1751. 
ta consultiva para asuntos americanos creada por Ensenada. El reconocimiento a su gestión por parte de sus superiores no se hizo esperar:

“[...] Atendiendo el Rey al distinguido mérito de D. Juliản de Arriaga, Jefe de escuadra de su Real Armada, y al particular que ha hecho, desempeñando su Real confianza en los empleos de gobernador y capitán general de la provincia de Venezuela y ciudad de Santiago de León de Caracas, se ha dignado SM por señal de su gratitud concederle la llave de Gentilhombre de Cámara de entrada, y lo aviso a VS de orden de SM a fin de que disponga se expida el correspondiente decreto... "92

El 23 de noviembre de 1751 recibió el nombramiento oficial de intendente general de la Marina del departamento de Cádiz y presidente del tribunal de la Casa de la Contratación de Indias, uno de los cargos más importantes y mejor pagados de la Administración de la Marina ${ }^{93}$. En la Real Orden se especifica que el nombramiento era en atención a sus buenos méritos y servicios, entre ellos los que últimamente habia realizado como gobernador de Venezuela ${ }^{94}$.

El nombramiento no sóio fue la recompensa por su labor de pacificador de una rebelión que habia causado mucha preocupación en la Corte, al poner en peligro las importaciones de cacao. Desde que Patiño creara el cargo de Intendente de la Marina en Cádiz $^{95}$, nombrando a Francisco de Varas, este era un puesto que, por ser el organismo ejecutor de las decisiones de la Secretaría de Marina a la vez que controlador de todos los gastos del mayor departamento marítimo y del comercio de Indias, requería a alguien de máxima confianza de los ministros de Marina. Los sucesores de Patiño al frente de la Secretaría de Marina habian mantenido a Varas en el cargo, a lo que debió contribuir su reconocida honestidad, la cual confirmará a Ensenada el propio Arriaga cuando, a los seis meses de haber sucedido en el cargo de Intendente al anciano Francisco de Varas, comunique al ministro el fallecimiento de éste ${ }^{96}$.

No obstante, en 1751, aprovechando la solicitud de retiro del servicio hecha por el propio Varas, Ensenada decidió jubilarlo con todos los honores, ascendiéndole antes a teniente general ${ }^{97}$, para entregar este cargo, decisivo para el funciona-

92 Archivo Palacio Real (APR), Personal. Caja 9005/7. San Lorenzo, 5 de noviembre de 1751. Carta de Ensenada al marqués de Campo Villar.

${ }_{93} \mathrm{MN}, \mathrm{Ms} .2094$, "Listado de oficiales de guerra sueltos de la Armada", folio 24. AGMAB, leg. 3095. Arriaga percibió como intendente de Marina un sueldo de 12.000 escudos al año.

94 AGMAB, leg. 620/86. Copia de R.O. con el nombramiento de 9 de noviembre de 1751.

95 Para profundizar en el conocimiento de la Intendencia de Marina de Cádiz consultar: A. CRESPO SoLANA, La Casa de la Contratación y la intendencia General de Marina de Cádiz (1717-1730), Cádiz, 1996.

${ }^{9}$ AGS, SM, leg. 16-1, exp. 5. Arriaga a Ensenada junio de 1753: "[...] murió Varas y se verifica el desinterés con que sirvió por no haber dejado en dinero ni aún lo que heredó de su hermana Dña. Margarita. Si VE quiere atender su memoria en el sobrino, será de ningún ejemplar ni perjuicio hacerle capitán de navío, y no estando para navegar, pedirá sin dificultad su jubilación».

97 AGMAB, leg. 3.095: "[...] habiendo tenido SM a bien admitir la dimisión que ha hecho el referido $D$. Francisco de Varas y Valdés de los empleos de la Presidencia del Tribunal de la Casa de la Contratación de Indias e Intendencia general del departamento de Marina de Cádiz a causa de su avanzada edad, y no poder por esta razón continuar en servirlos con la aplicación y vigilancia con que a procedido, ha practicado concederle los honores de Teniente General de sus Reales Ejércitos...". 
miento de la Marina y de los asuntos de Indias, a alguien en quien realmente confiaba y que le había demostrado con su reciente actuación estar capacitado para ejercer semejante responsabilidad. Para Arriaga, a sus casi cincuenta y dos años, el cargo supuso el broche de oro a su carrera de marino, a la vez que el principio de una nueva etapa de su vida completamente distinta. Cambió la incomodidad de la vida a bordo, el riesgo de la navegación y del servicio en la Armada, por la tranquilidad y seguridad del despacho de un miembro de la alta administración del Estado.

Para cualquier marino vocacional, y Arriaga lo fue, dejar la mar a pesar de su edad y mala salud ${ }^{98}$ no debió ser fácil. Ensenada confiaba en él y lo necesitaba para un puesto decisivo que supo hacerle atractivo al entregarle todo el poder del cargo, arriesgando mucho. Si tenemos en cuenta que la mayoria de los marinos cuando dejaban de navegar se jubilaban sin más, y que como algo muy excepcional sólo muy pocos conseguían algún cargo en la administración de la Marina, a Arriaga "le tocó el gordo" en la lotería de cargos y nombramientos.

Una vez en el poder no quiso perderlo, pues no dudó en participar en la intriga que tramaron, en la primavera de 1754, el duque de Huéscar, el secretario de Estado, Ricardo Wall, y el embajador inglés, Benjamin Keene, para derrocar a Ensenada, convirtiéndose en su sucesor en las carteras de Marina e Indias, y traicionando a quien tanto le había ayudado y confiado en él.

Tenemos conocimiento detallado de la intriga gracias a los despachos diplomáticos que Benjamin Keene envió a Thomas Robinson, en los que le fue informando de la evolución de la conjura con todo detalle ${ }^{99}$. En uno de esos despachos confirmó la participación directa de Arriaga en la conjura ${ }^{100}$.

En efecto, los cargos administrativos que le encomendó Ensenada, supusieron para Arriaga un trampolín para alcanzar las Secretarías de Marina e Indias. El duque de Huéscar y Ricardo Wall, para sustituir a Ensenada, buscaron un perfil de secretario que fuera buen conocedor de los asuntos de la Marina e Indias, honrado y, sobre todo, de carácter sumiso y senvil para poderle controlar. A pesar de que Arriaga había sido hechura de Ensenada y había gozado de la confianza de éste, tenía a su favor que, al haber estado embarcado hasta el otoño de 1752 y posteriormente haber fijado su residencia en Cádiz, apenas habia podido implicarse en las intrigas cortesanas de los miembros de su red y, sobre todo, que no habia dudado en renegar de su benefactor.

98 Allan J. Kuethe: Cuba, 1753-1815, Crown, Military, and Society, The University of Tennessee Press, Knoxville, 1986, pp. 27-28.

${ }^{99}$ W. COXE. España bajo el reinado de la Casa de Borbón. Desde 1700 en que subió al trono Felipe $V$ hasta la muerte de Carlos III acaecida en 1788, 4 vols. Madrid, 1846-1847. T. III, pp. 402-413.

100 "[...] Como Arriaga había recibido el ascenso de Ensenada, hice alguna objeción ante él cuando se estaba estableciendo el plan para el nuevo ministerio antes de la caída de Ensenada, pero él respondió que eso que él, Arriaga, hizo bajo Ensenada era contra el corazón; y que si no va a actuar bien en el futuro, será muy fácil quitarle». En C. González CAIZÁN: La red política de Zenón de Somodevilla y Bengoechea, marqués de la Ensenada, tesis doctoral inédita, La Rioja, 2002, pp. 142. 
Así pues, consumada la intriga y detenido Ensenada y sus más íntimos colaboradores, Arriaga se convirtió en Secretario de Estado y del Despacho de Mari$\mathrm{na}^{101}$, conservando ínicialmente Wall la secretaría de Indias tras separarla de la de Marina, aunque terminó por entregársela también a Arriaga en agosto ${ }^{102}$. No obstante, para evitar que acumulara tanto poder como había tenido su antecesor, se especificaron por real decreto los cometidos de cada Secretaría, y se estableció que ambas pasaran aviso a la de Hacienda de todos los gastos extraordinarios para que fuese esta secretaría la que los proveyese ${ }^{103}$.

Con la finalidad de redondear su propio currículum, en la primera promoción de oficiales de Marina que llevó a cabo como ministro, se incluyó entre los jefes de escuadra que ascenderian a tenientes generales ${ }^{104}$. A estas alturas de su vida Arriaga había llegado mucho más lejos de lo que jamás hubiera soñado. Un pequeño hidalgo segundón había alcanzado las más altas cotas de poder posibles en el Antiguo Régimen para alguien de su procedencia social: sólo le quedaba aspirar a conservarlas y esperar las mercedes que, por su cercanía al monarca, éste tuviera a bien concederle. Pero Carlos III, que tan generoso fue con todos los ministros que le sirvieron, sólo en este aspecto no lo fue con Arriaga. Prácticamente a todos sus ministros, en los primeros años de sus respectivos mandatos los hizo miembros de su Consejo de Estado y, como no pertenecían al estamento nobiliario, les concedió título de Castilla entre otras prebendas, pero a Arriaga, a pesar de apoyarlo y mantenerlo en el cargo durante casi veintidós años, no lo ennobleció y esperó a nombrarle Consejero de Estado hast $1771^{105}$, aprovechando el nacimiento del infante Carlos Clemente, que moriría pocos años después.

Arriaga se mantuvo en el cargo de ministro hasta su muerte ocurrida en enero de 1776, a los setenta y cinco años, estando de jornada en El Pardo ${ }^{106}$.

101 A.H.N., Estado, leg. 2874, exp. 16: «Buen Retiro, 22 de julio de 1754, Habiendo depuesto el Rey por resolución del día 20 del corriente al marqués de la Ensenada de todos sus empleos y encargos, desterrándole a Granada, se ha servido conferir a VE la Secretaria de Marina. Me manda participarlo a VE para que se ponga luego en camino para esta Corte a tomar posesión de su nuevo empleo, pero gobernando su marcha y jornadas sin perjuicio de su salud, y dejar a la elección de Ud. El nombrar sujeto que interinamente cuide de los encargos que le estaban acometidos en ese departamento". La Gaceta de Madrid publicó el 23 de julio de 1754 un texto muy parecido incluyendo los nombramientos de los otros ministros. A.H.N., Estado, leg., 3497. Título de Secretario de Marina, rubricado por Fernando VI el 25 de julio de 1754.

102 A.H.N., Estado, leg. 3.497. Título de Secretario de Indias, 9 de septiembre de 1754.

103 Ibídem. Real decreto de 26 de agosto de 1754 enviado a Arriaga por Wall especificando las competencias de las dos Secretarías a su cargo.

104 AGMAB, C.G. leg. 534, 30 de mayo de 1755. Ascendieron a tenientes generales los jefes de escuadra Ignacio Dautevill, Pedro de la Cerda, Francisco Orozco y Julián de Arriaga. A capitanes de navío: Daniel Huoni, Isidro de Antaio, marqués de Vistalegre, Carlos Reggio, el conde de Vegaflorida y Blas de la Barreda. Como sucesor suyo en la Intendencia de Cádiz nombró a Juan Gerbaut. Ascendió a todos aquellos que habían sido sus compañeros de armas en muchas de las campañas eri las que participó.

105 A.H.N., Estado, leg. 2475, San Lorenzo, 23 de octubre de 1771: “Excmo. Sr., en atención a las circunstancias, méritos y dilatados e importantes servicios de VE al Rey, ha venido el rey en concederle plaza en el Consejo de Estado con la casa de aposento y emolumentos correspondientes, libre de media annata, lo que participo a VE para su noticia, satisfacción y ruego'. AGMAB, Secretaría, leg. 5058. Notificación del nombramiento del secretario del Consejo de Estado a Arriaga.

${ }^{106}$ Gaceta de Madrid, 6 de febrero de 1776. 
Tras convertirse en secretario de Marina e Indias en el verano de 1754, Arriaga instaló su domicilio en Madrid, en la calle Alta de Fuencarral, permaneciendo en él hasta su muerte ${ }^{107}$. El recibidor de la Orden de San Juan para el priorato de Castilla, es decir el encargado de las finanzas, era quien se hacía cargo de los bienes de los freyres tras su muerte. Entre sus obligaciones estaba la de realizar el inventario de todas las pertenencias dejadas por los caballeros tras su fallecimiento (dinero, joyas, plata, mobiliario, ropa, carruajes, enseres domésticos, etc.) y organizar la venta de las mismas. Tanto el importe de la venta como las pertenencias restantes pasaban a la Orden. El expolio de los bienes dejados por el bailio Arriaga una vez satisfechas todas las obligaciones, pagado el funeral y realizada la venta, refleja un cargo a favor de la Orden de 294.410 ducados y 30 maravedis $^{108}$.

El apartado de alhajas del inventario de bienes consta de dos veneras, una de diamantes y otra de oro, que eran las insignias distintivas que los caballeros y bailíos portaban en el pecho, así conno de dos cordones, uno de oro y otro de plata, probablemente parte del hábito de los caballeros. Es muy significativo que Arriaga, un ministro de la Corte acostumbrado a recibir en su casa a sus compañeros de gabinete, embajadores, miembros de los Consejos, asi como a otros personajes de la alta sociedad, no dejara ni cuberteria, ni vajilla, ni servicio de mesa de plata, como si dejaron otros caballeros sanjuanistas que al parecer, sin gozar del alto nivel social de Arriaga, vivieron rodeados de más lujo ${ }^{109}$.

\section{CONCLUSIONES}

La semblanza de Arriaga surgida de la investigación nos ha aportado una imagen más completa, profunda y acorde con los acontecimientos que le habian tocado vivir que la que hasta ahora nos había transmitido la historiografía. La vida del que llegara a ser un poderoso ministro de Marina tuvo tres etapas muy diferenciadas. Tras una infancia y adolescencia transcurridas en Burgos, Arriaga pasó un largo período de once años de formación y posterior colaboración con la Orden de Malta, hasta que ingresó directamente en el Cuerpo General de la Real Armada, sin pasar por la Escuela de Guardias Marinas, desarrollando su carrera de marino.

La documentación nos ha permitido descubrir, en primer lugar, a un hidalgo segundón, nacido en una familia castellana que tradicionalmente destinaba sus hijos a la administración provincial del Estado, al Ejército o a la Iglesia, y que se convirtió en secretario de Estado de Marina e Indias, uno de los cargos políticos más poderosos e influyentes de la Monarquia. Fue un hombre que durante toda su vida se preocupó por el bienestar de los suyos, apoyándoles económicamente de forma

107 Guía de Forasteros, años 1754-1776.

109 Ibidem. Expolıo del comendador Frey D. Joaquín de Guzmán. 
muy generosa, incluso antes de llegar a ser ministro y convertirse en un hombre rico. Cuando sólo contaba con su sueldo de marino y una pequeña renta como caballero sanjuanista, la cedió a sus hermanas religiosas para su manutención, y ya siendo ministro se preocupó de conseguir pensiones para su cuñada viuda y sus sobrinos.

Descubrimos también a un marino vocacional, que permaneció veinticuatro años navegando en alguna de las escuadras de la Real Armada de la Monarquia, lo que implica que sufrió todo tipo de avatares, desde naufragios hasta enfrentamientos contra ingleses o argelinos. Eso sin contar con la dureza habitual de la vida a bordo.

Desde el principio de su carrera como marino supo granjearse la confianza de sus superiores, con cuyo apoyo fue consiguiendo ascensos, nombramientos y cargos. Esta cualidad la cultivó hasta el final de sus dias ya que el propio Carlos III apoyó a su ministro de Marina hasta su muerte, y no porque éste no le diera motivos para ser destituido, o por falta de un sustituto (como percibió el embajador austriaco conde Rosenberg), ni porque al monarca le costara cambiar las personas de su círculo más cercano (como afirman muchos de sus biógrafos), ya que cuando tuvo que cesar a algún ministro, por muy querido que le resultase, no le tembló el pulso al hacerlo, bastando con recordar las destituciones de sus secretarios de Estado Wall, Esquilache o Grima!di.

Hemos visto cómo su relación con Ensenada fue decisiva para su carrera política. Ensenada confió plenamente en él, dándole la oportunidad de participar en las más brillantes campañas desarrolladas durante su mandato. Arriaga no le defraudó por lo que Ensenada también le encomendó la jefatura de dos de las campañas más delicadas que emprendió durante su mandato: la reanudación del corso contra los argelinos tras la Paz de Aquisgrán en 1748, y el sometimiento de la rebelión contra la Compañía de Caracas en 1751, que Arriaga resolvió muy satisfactoriamente, consiguiendo como premio el nombramiento de Gentilhombre de Cámara y el cargo de Intendente del Departamento de Cádiz. Este cargo supuso el inicio de una tercera etapa de su vida muy diferente de las anieriores, que desarrolló en la Administración de la Marina.

Arriaga pasó de ensenadista de pro y hombre de confianza del todopoderoso ministro a participar en la conjura que culminó con la destitución de Ensenada. Traicionó a quien tanto confió en él para convertirse en ministro de Marina.

Finalmente, tal vez, su largo entrenamiento sorteando los peligros de la navegación en sí misma y los enfrentamientos bélicos propios de su actividad como marino de guerra propiciaron que desarrollara la prudencia y la astucia, cualidades que posteriormente le sirvieron para campear los temporales políticos que se le vinieron encima, en su larga etapa como ministro de Marina e Indias. 